\title{
Expedient nonclassical reaction of acetylenes with ketones: controlling the switch between bicyclic ketal and cyclopentenol formation
}

\author{
Elena Yu. Schmidt, Ivan A. Bidusenko, Natalia A. Cherimichkina, and Boris A. Trofimov* \\ Laboratory of Unsaturated Heteroatomic Compounds, \\ A.E. Favorsky Irkutsk Institute of Chemistry, Siberian Branch, Russian Academy of Sciences \\ 1 Favorsky Str., 664033 Irkutsk, Russia \\ E-mail: boris_trofimov@irioch.irk.ru
}

DOI: http://dx.doi.org/10.3998/ark.5550190.p009.302

\begin{abstract}
The condition-controlled switch between the bicyclic ketals, 7-methylene-6,8dioxabicyclo[3.2.1]octanes and 3-acyl-2-cyclopenten-1-ols formation during the 2:2 selfassembly of acetylenes with ketones in the presence of the $\mathrm{KOH} / \mathrm{DMSO}$ suspension at $30-70{ }^{\circ} \mathrm{C}$ has been developed. The selectivity reaches ca. 100\% for bicyclic ketals and $67 \%$ for cyclopentenols. Both reactions are diastereoselective.
\end{abstract}

Keywords: Acetylenes, ketones, 6,8-dioxabicyclo[3.2.1]octanes, cyclopentenols, C-C bond formation

\section{Introduction}

The development of new reactions leading to the formation of $\mathrm{C}-\mathrm{C}$ and $\mathrm{C}-\mathrm{O}$ bonds, constructing biologically and pharmaceutically important structures via a single-reactor methodology, represents a long-standing challenge of fine organic synthesis. Acetylene and other alkynes, owing to their high and diverse reactivity, are frequently used to respond to this challenge. Now this trend ${ }^{1-4}$ gains strength due to the depletion of fossil hydrocarbons. Consequently, new methods (including those based on coal) ${ }^{1,5}$ for acetylene production arise. Over many years, fundamental organic synthesis has revealed a diversity of reactions of alkynes, which provide new C-C, C-N, and C-O bond formation, e.g. in important biomolecules as pyrroles, ${ }^{6,7}$ pyridines, ${ }^{2,8-10}$ vitamins A and $\mathrm{E},{ }^{1,11} \beta$-carotene, ${ }^{11}$ linalool, ${ }^{11}$ citral, ${ }^{12}$ steroids, ${ }^{13,14}$ etc. In this area of organic synthesis, the application of superbasic media such as alkaline metal hydroxide or alkoxide/DMSO ${ }^{15}$ to promote the reactions of alkynes with nucleophiles is a comparatively underestimated approach. However, some impressive results have already been reported 
including one-pot alkyne-based syntheses of azulenones, ${ }^{16}$ pyrroles, ${ }^{15,17}$ 7-methylene-6,8dioxabicyclo[3.2.1] octanes $^{18,19} \quad \Delta^{2}$-isoxazolines, ${ }^{20}$ and 4-methylene-3-oxa-1azabicyclo[3.1.0] hexanes. ${ }^{21}$ An intriguing feature of the superbasic medium KOH/DMSO is its tunability, i.e. the ability to change considerably the character of its catalytic activity. ${ }^{15,22,23}$ This stems from the limited solubility of $\mathrm{KOH}$ in DMSO which forms a suspension consisting of microcrystals, nanoparticles, diverse associates and a true molecular solution. These are in temperature-, concentration- and solvent-dependent dynamic equilibrium, thus mimicking a kind of living system. ${ }^{23}$

We have recently shown that the one-pot assembly of 3-methyl-7-methylene-1,5-diphenyl6,8-dioxabicyclo[3.2.1] octane (having the pheromone frontaline scaffold) ${ }^{24-27}$ from acetophenone 1a and acetylene 2a promoted by a KOH/DMSO suspension (Scheme 1) is accompanied by the formation of a minor product (yield $<1 \%$ ), 3-benzoyl-2,4-dimethyl-1-phenyl-2-cyclopenten-1-ol (4a), a structural isomer of the bicyclic ketal 3a.

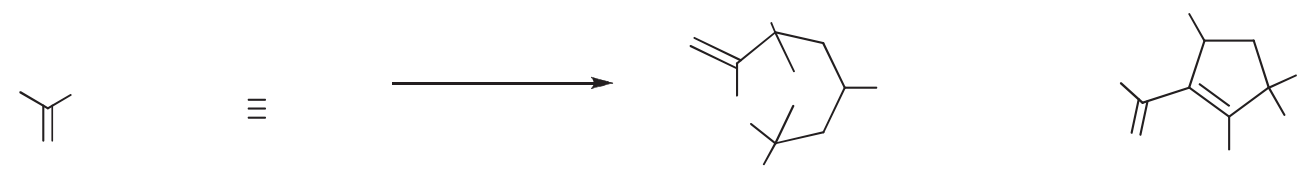

Scheme 1. The reaction of acetophenone $\mathbf{1 a}$ with acetylene $\mathbf{2} \mathbf{a}$ in the KOH/DMSO system.

Like the bicyclic ketal 3a, the cyclopentenol 4a is also built up from two molecules of ketone 1a and two of the acetylene 2a. A fascinating feature of this four-molecular self-organization is the regio- and stereoselectivity: both structural isomers $\mathbf{3 a}$ and $\mathbf{4 a}$ are formed exclusively as single diastereomers despite the presence of several asymmetric carbons. Later, we succeeded in turning this negligible side reaction into the major one. ${ }^{28}$

Since both 6,8-dioxabicyclo[3.2.1] octanes and cyclopentenols are closely related to valuable naturally occurring compounds ${ }^{24-27}$ and known drugs, ${ }^{29-34}$ the improvement of their accessibility deserves additional endeavor. Herein we summarize the results of our systematic study to elaborate a practical and scalable synthesis of both 6,8-dioxabicyclo[3.2.1]octanes and cyclopentenols in one synthetic operation.

\section{Results and Discussion}

Table 1 contains selected data giving an insight into the effect of the conditions on the products yield and ratio for the reaction between acetophenone $\mathbf{1 a}$ and acetylene $\mathbf{2 a}$ in the KOH/DMSO suspension. 
Table 1. The reaction of acetophenone 1a with acetylene 2a in the presence of the KOH/DMSO suspension (Scheme 1): tuning the yield and ratio of the products by changing the reaction conditions $^{a}$

\begin{tabular}{ccccccc}
\hline Entry & $\begin{array}{c}\text { KOH:1a } \\
\text { Molar ratio }\end{array}$ & $\begin{array}{c}\text { Temp } \\
\left({ }^{\circ} \mathrm{C}\right)\end{array}$ & $\begin{array}{c}\text { Time } \\
(\mathrm{min})\end{array}$ & $\begin{array}{c}\text { Conversion } \\
\text { of } \mathbf{1 a}(\%)\end{array}$ & $\begin{array}{c}\text { 3a:4a Molar } \\
\text { ratio }^{b}\end{array}$ & $\begin{array}{c}\mathbf{3 a}+\mathbf{4 a} \text { Total } \\
\text { yield }(\%))^{c}\end{array}$ \\
\hline 1 & $1: 1$ & 70 & 15 & 100 & $99: 1$ & 94 \\
2 & $1: 1$ & 50 & 15 & 100 & $89: 11$ & 84 \\
3 & $1: 1$ & 40 & 15 & 78 & $77: 23$ & 63 \\
4 & $1: 1$ & 30 & 15 & 46 & $50: 50$ & 41 \\
5 & $1: 2$ & 70 & 15 & 100 & $91: 9$ & 90 \\
6 & $1: 4$ & 70 & 15 & 100 & $91: 9$ & 92 \\
7 & $1: 8$ & 70 & 15 & 100 & $83: 17$ & 93 \\
8 & $1: 15$ & 70 & 15 & 88 & $38: 62$ & 87 \\
9 & $1: 15$ & 70 & 60 & 93 & $38: 62$ & 75 \\
10 & $1: 15$ & 70 & 180 & 94 & $37: 63$ & 82 \\
11 & $1: 15$ & 70 & 240 & 96 & $36: 64$ & 85 \\
12 & $1: 15$ & 70 & 480 & 100 & $38: 62$ & 98 \\
\hline
\end{tabular}

${ }^{a}$ Reagents and conditions: initial pressure of acetylene 2a at ambient temperature was 12-14 atm, acetophenone 1a (17 mmol, $2.00 \mathrm{~g})$, DMSO $(50 \mathrm{~mL}) .{ }^{b}$ Determined from ${ }^{1} \mathrm{H}$ NMR data of the reaction mixtures. ${ }^{c}$ Isolated yields after column chromatography (basic $\mathrm{Al}_{2} \mathrm{O}_{3}$, hexane, $\mathrm{CHCl}_{3}$ ).

As can be seen from Table 1, the tuning of the catalytic system by the decrease of $\mathrm{KOH}$ :ketone 1a molar ratio from 1:1 to 1:15 leads to a drastic inversion of the products ratio, virtually to the switch from the preferable formation of bicyclic ketal 3a to cyclopentenol 4a (from 99:1 to 36-38:62-64, $c f$. entries 1 and 8-12). A similar change of the products ratio up to 50:50 occurs by affecting the catalytic activity of the $\mathrm{KOH} / \mathrm{DMSO}$ system via the reaction temperature decrease from 70 to $30{ }^{\circ} \mathrm{C}$ (entries 1-4), although the conversion of acetophenone 1a expectedly drops from 100 to $46 \%$.

The switchable nature of the reaction is clearly demonstrated by the experiments in which the reaction mixture basicity is lowered by the addition of water. Even the addition of $1 \%$ of water to the reaction mixture $\left(1: 1 \mathrm{KOH}\right.$ :ketone $1 \mathrm{a}$ molar ratio, $\left.70{ }^{\circ} \mathrm{C}, 15 \mathrm{~min}\right)$ dramatically alters the 3a:4a molar ratio (from 99:1 to 58:42). At higher water content in the reaction mixtures (5 and $10 \%$ of water), the 3a:4a molar ratio is retained, while the conversion and the yield diminish (for $5 \%$ to 61 and $43 \%$, for $10 \%$ to 59 and $34 \%$ ).

The reaction products $\mathbf{3} \mathbf{a}$ and $\mathbf{4 a}$ are easily and cleanly separated by column chromatography (basic $\mathrm{Al}_{2} \mathrm{O}_{3}$, first dioxabicyclooctane $3 \mathbf{a}$ is washed off with $n$-hexane, and then cyclopentenol $\mathbf{4 a}$ is washed with $\mathrm{CHCl}_{3}$ ). A surprising feature of the cyclopentenol $\mathbf{4 a}$ assembly is the unusually 
small amount of basic species needed for its optimum formation, while to attain the highest yield of dioxabicyclooctane 3a, a 15-fold higher concentration of base is crucial.

Until now the true scope of this double-faced reaction remained obscure. In accordance with the best conditions for the simultaneous synthesis of compounds 3a and 4a (Table 1), the relation between the substrate structure and the products yield and ratio was studied and the reactions were carried out with a 1:15 KOH:ketone 1 molar ratio.

Table 2 shows that the assembly of bicyclic ketals 3 and cyclopentenols $\mathbf{4}$ from ketones and acetylene tolerates both acetylarenes 1a-c and acetylhetarenes 1d,e. For all the ketones, the total yields $(\mathbf{3}+\mathbf{4})$ range $72-98 \%$. Under these conditions, the conversion of the starting ketones $\mathbf{1}$ is close to $100 \%$. An unexpected result is that in the case of 4-acetylpyridine 1d, the assembly proceeds with complete loss of the pyridyl carbonyl function to deliver cyclopentenol $\mathbf{4} \mathbf{d}^{\prime}$.

Table 2. Substrate scope and the products yield and ratio for the reaction of ketones 1a-e with acetylene $\mathbf{2} \mathbf{a}$ in the presence of the KOH/DMSO system ${ }^{a}$
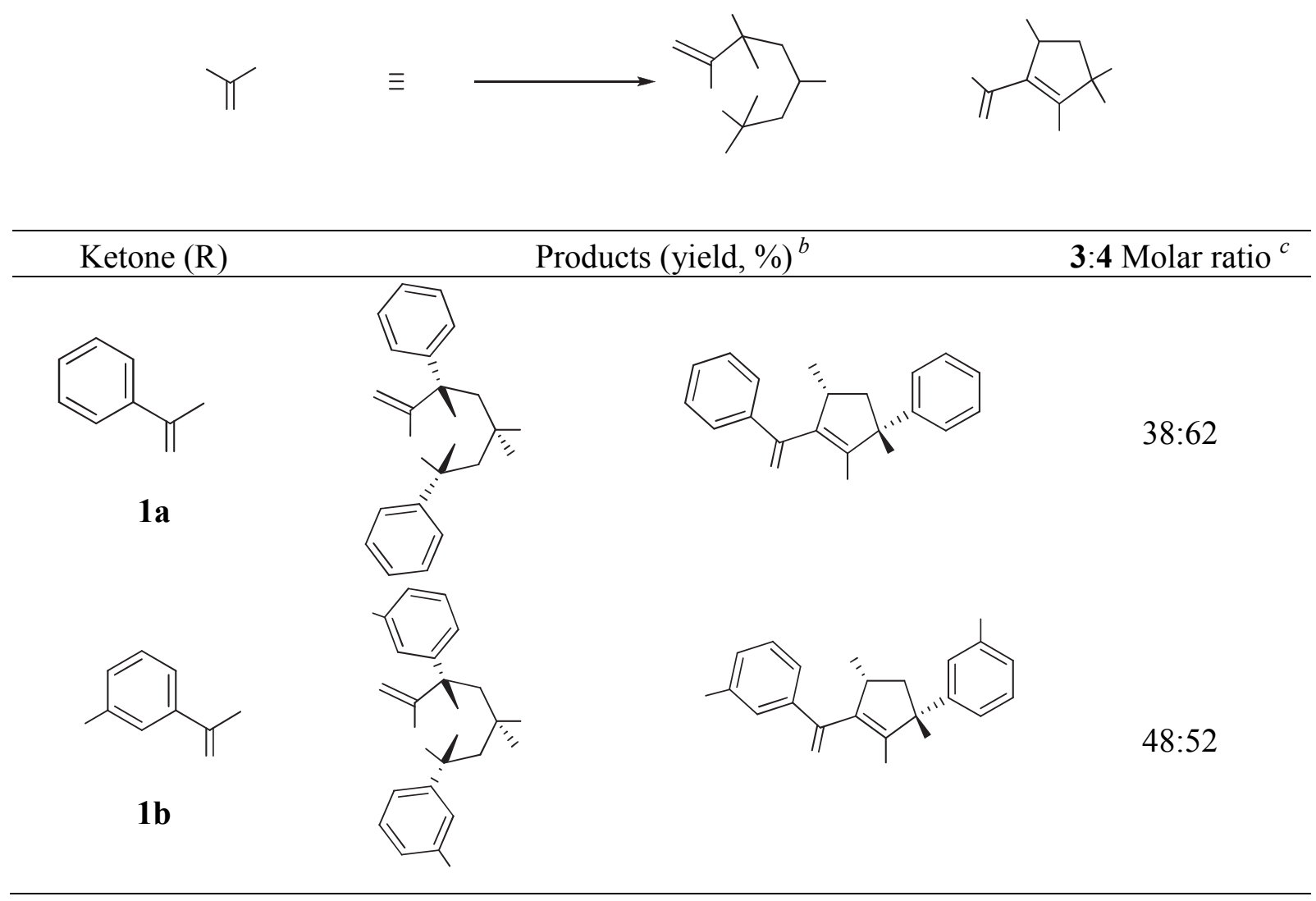
Table 2 (continued)

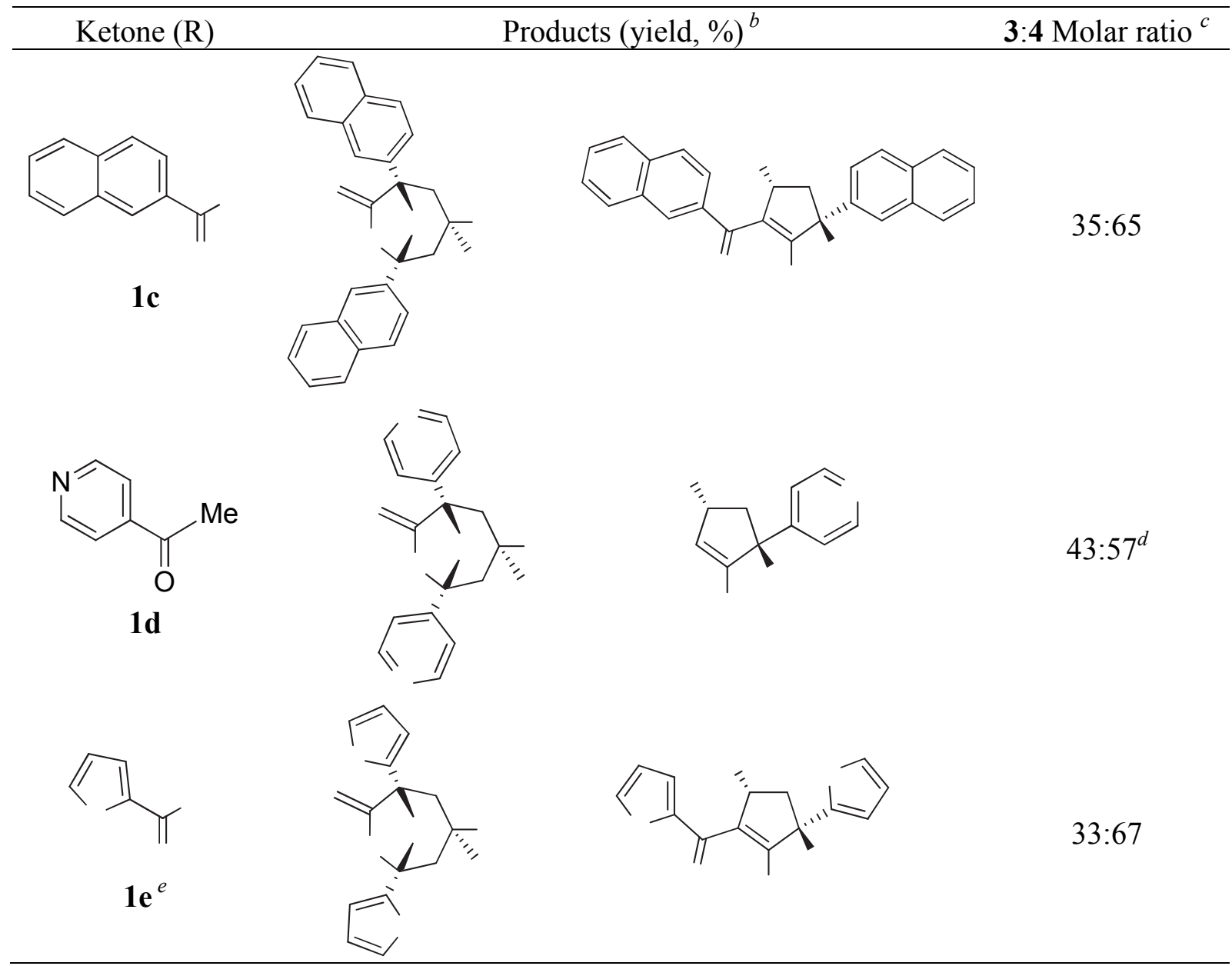

${ }^{a}$ Reagents and conditions: ketone $1(17.0 \mathrm{mmol}), \mathrm{KOH} \cdot 0.5 \mathrm{H}_{2} \mathrm{O}(0.07 \mathrm{~g}, 1.1 \mathrm{mmol})$, DMSO (50 $\mathrm{mL}$ ), initial pressure of acetylene $\mathbf{2 a}$ at ambient temperature was 12-14 atm (stirred reactor). ${ }^{b}$ Isolated yield after column chromatography (basic $\mathrm{Al}_{2} \mathrm{O}_{3}$, hexane, $\mathrm{CHCl}_{3}$ ). ${ }^{c}$ Determined from ${ }^{1} \mathrm{H}$ NMR data of the reaction mixtures. ${ }^{d} \mathbf{3 d}: \mathbf{4 d}$ ' Molar ratio. ${ }^{e}$ The reaction was carried out at $80{ }^{\circ} \mathrm{C}$ using $\mathrm{KOH}:$ ketone $1 \mathrm{e}$ molar ratio $=1: 2$.

Some decrease of the cyclopentenol $\mathbf{4 b}$ content in the crude product in case of ketone $\mathbf{1 b}$, as compared to the unsubstituted acetophenone 1a (38:62 vs. 48:52, Table 2), may be explained by a lower nucleophilicity of the corresponding carbanion due to the electron-accepting effect of the meta-methoxy substituent.

The key intermediates of this switchable reaction are 1,5-diketones $\mathbf{5}$, which further undergo the Favorsky ethynylation and subsequent ring closure in the acetylenic ketoalcoholate $\mathbf{A}$ to give ketals $\mathbf{3}$ (Scheme 2). The intermediates $\mathbf{5}$ themselves result from the nucleophilic addition of two molecules of a ketone $\mathbf{1}$ to acetylene 2a (first, C-vinylation of the ketone 1, then prototropic 
rearrangement of the adduct and Michael addition of the second molecule of deprotonated ketone to the $\alpha, \beta$-unsaturated ketone).

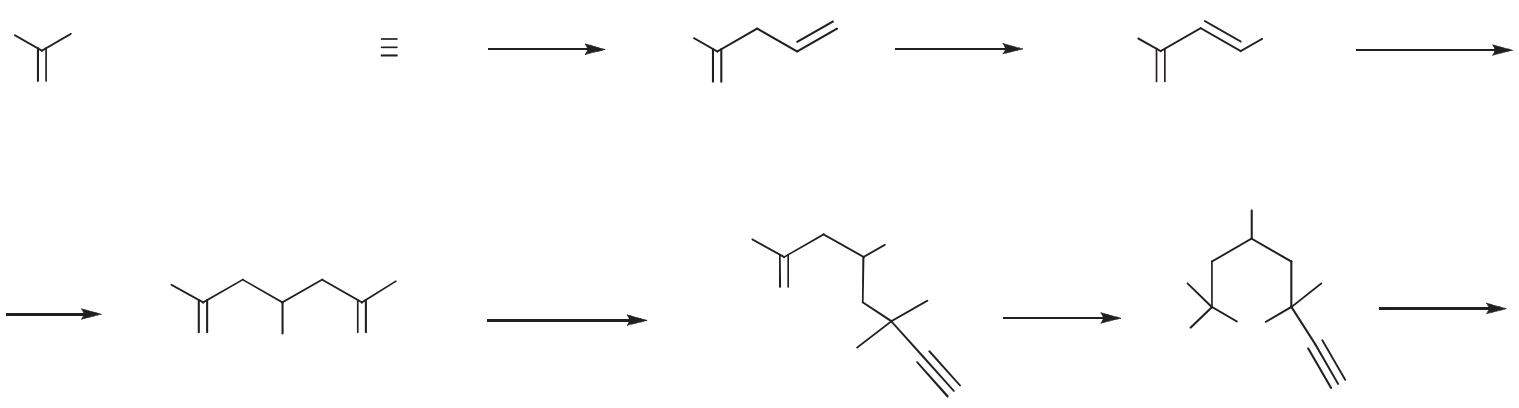

Scheme 2. The assembly of 7-methylene-6,8-dioxabicyclo[3.2.1]octanes 3.

The diastereoselectivity of this assembly (Scheme 2) is secured by the final ring closure that can occur only when the hydroxy and ethynyl groups are in a cis-orientation relative to the distorted tetrahydropyrane plane of hemi-ketal $\mathbf{B}$.

Obviously, the cyclopentane ring closure originates from the addition of carbon-centered anion $\mathbf{C}$ to the triple bond (Scheme 3) that should precede and compete with the formation of hemiacetal intermediate $\mathbf{B}$ (Scheme 2).

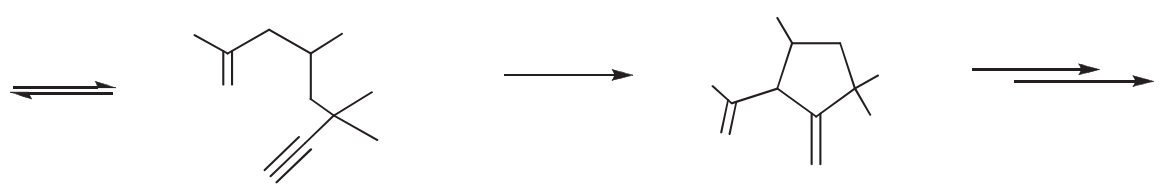

Scheme 3. A tentative mechanism for the formation of 3-acyl-2-cyclopenten-1-ols 4.

A likely model of the diastereoselectivity of the cyclopentenol 4 assembly (Scheme 3 ) is the template effect of the potassium cation which retains an enolizable carbonyl function and a hydroxyl group on one side of the closing ring.

Now it is understandable how the decrease in $\mathrm{KOH}$ content slows down the rate of hemiacetal $\mathbf{B}$ formation and the nucleophilic addition of the O-centered anionic site to the triple bond (i.e. the assembly of bicyclic ketals 3, Scheme 2), and why, in this case, the competitive formation of cyclopentenols $\mathbf{4}$ is favored. It follows that the intramolecular C-vinylation (assembly of cyclopentenols 4, Scheme 3) is not so sensitive to the basicity of the medium. Apparently, at a lower concentration of $\mathrm{KOH}$, the conformations with anti-orientation of the $\mathrm{C}=\mathrm{O}$ and $\mathrm{OH}$ groups become less populated, and hence the $\mathrm{C}$-vinylation gains the competition. 
Notably, the assembly of cyclopentenols $\mathbf{4}$ is limited to methylaryl(hetaryl)ketones only. When ethyl or other alkyl aromatic or heteroaromatic ketones are employed, exclusively bicyclic ketals $\mathbf{3}$ are regio- and stereoselectively assembled, obviously due to the sterically hindered access of a branched carbanionic center to the acetylenic moiety in the intermediate $\mathbf{C}$ (Scheme 3 ).

In the light of the proposed mechanism, 7-methylene-6,8-dioxabicyclo[3.2.1] octanes 3 and 3acyl-2-cyclopenten-1-ols 4 might also be assembled from acetylenes and 1,5-diketones $\mathbf{5}$, readily available via the aldol condensation of aldehydes with two molecules of ketone. ${ }^{35-37}$ The reaction of 1,5-diketones 5a-c with acetylenes $\mathbf{2 a}, \mathbf{b}$ has been conducted under the best conditions selected from numerous experiments, in which the major reaction parameters (the catalyst and reactants molar ratio, reaction temperature and time) were varied (Table 3). These conditions allow the complete conversion of 1,5-diketones $\mathbf{5}$.

Table 3. The product yields and ratios for the reaction of 1,5-diketones 5a-c with acetylenes $\mathbf{2 a}, \mathbf{b}$ in the presence of the $\mathrm{KOH} / \mathrm{DMSO}$ system $(\mathrm{KOH}$ :diketone 5 molar ratio = 1:2)

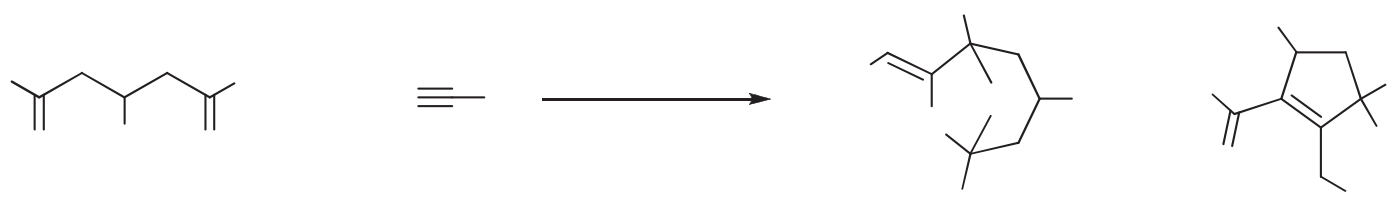

1,5-Diketone $\left(\mathrm{R}^{1}\right)$ Acetylene $\left(\mathrm{R}^{2}\right)$


Table 3 (continued)

1,5-Diketone $\left(\mathrm{R}^{1}\right)$ Acetylene $\left(\mathrm{R}^{2}\right) \quad$ Products (yield, \%) ${ }^{a}$

${ }^{a}$ Isolated yield after column chromatography (basic $\mathrm{Al}_{2} \mathrm{O}_{3}$, hexane, $\mathrm{CHCl}_{3}$ ). ${ }^{b}$ Determined from ${ }^{1} \mathrm{H}$ NMR data of the reaction mixtures. ${ }^{c}$ The reactions were carried out with acetylene $2 \mathbf{a}$ [initial pressure at ambient temperature was 12-14 atm (stirred reactor)], 1,5-diketone 5 (6 $\mathrm{mmol}), \mathrm{KOH} \cdot 0.5 \mathrm{H}_{2} \mathrm{O}(0.2 \mathrm{~g}, 3 \mathrm{mmol})$, DMSO $(50 \mathrm{~mL}) .{ }^{d}$ The reaction time was $0.5 \mathrm{~h} .{ }^{e}$ Diastereomers ratio $=3: 1 .{ }^{f}$ Phenylacetylene $\mathbf{2 b}(7.7 \mathrm{mmol})$.

From Table 3 it is seen that the synthesis of bicyclic ketals 3 and cyclopentenols 4 can be realized from both substituted acetylenes (such as phenylacetylene $\mathbf{2 b}$ ) and diverse 1,5-diketones 5. As anticipated, yields of the products and their ratios (as well as sometimes their structure) are controlled considerably by the substituents in 1,5-diketones 5. Similar to the direct reaction of ketones 1 with acetylene 2a (Table 2), in some cases, deacylation of cyclopentenols 4 occurs (formation of cyclopentenols $\mathbf{4}^{\prime}$ ). In the reaction of 1,5-diketone $\mathbf{5 b}$ with phenylacetylene $\mathbf{2 b}$, the formed cyclopentenol $\mathbf{4 h}$ is subjected to both deacylation and dehydration to the corresponding cyclopentadiene $\mathbf{4 h}$ " (Table 3 ).

\section{Conclusions}

In conclusion, it has been shown for the first time that self-organization of two molecules of acetylenes and two molecules of ketones in the KOH/DMSO superbasic suspension delivering 7methylene-6,8-dioxabicyclo[3.2.1] octanes and 3-acyl-2-cyclopenten-1-ols can be efficiently controlled by changing the catalyst content, temperature and basicity of the reaction mixture. The selectivity of 7-methylene-6,8-dioxabicyclo[3.2.1]octanes and 3-acyl-2-cyclopenten-1-ols formation is up to $100 \%$ and $67 \%$, respectively. Both products are easily separated and purified by column chromatography. Independent practical synthesis of bicyclic ketals and cyclopentenols has been developed from available 1,5-diketones, which have proven to be common key intermediates for both self-assemblies. Particularly important is that all the syntheses are strictly diastereoselective: only a single diastereomer is formed in all the cases, despite the presence of a number of stereogenic centers in all the molecules. 


\section{Experimental Section}

General. $\mathrm{KOH} \cdot 0.5 \mathrm{H}_{2} \mathrm{O}$, DMSO (with content of water $0.2-0.3 \%$ ) and all other chemicals and solvents are commercially available and were used without further purification. The elaborated procedure does not require degassing of DMSO and use of inert atmosphere. The 1,5-diketones were synthesized by using published procedure. ${ }^{38,39}{ }^{1} \mathrm{H}$ and ${ }^{13} \mathrm{C}$ NMR spectra were recorded at 400.13 and $100.61 \mathrm{MHz}$, respectively, on an instrument equipped with an inverse gradient $5 \mathrm{~mm}$ probe in $\mathrm{CDCl}_{3}$ with hexamethyldisiloxane (HMDS) as an internal standard. All 2D NMR spectra were recorded by using a standard gradient Bruker pulse program. Standard COSY spectra with a $90^{\circ}, 45^{\circ}$ pulse sequence were recorded. ${ }^{40}$ The NOESY spectra were recorded in the phase-sensitive TPPI mode with mixing time of 1-1.4 s. ${ }^{41}$ HSQC spectra via double INEPT transfer in the phase sensitive TPPI mode with GARP decoupling during acquisition were recorded. ${ }^{42}$ HMBC spectra were obtained with the inverse technique and processed in the magnitude mode. ${ }^{43}$

Typical procedure for the reaction of ketones 1a-e with acetylene 2a. A suspension of ketone 1a-e $(17.0 \mathrm{mmol})$ and $\mathrm{KOH} \cdot 0.5 \mathrm{H}_{2} \mathrm{O}(0.07 \mathrm{~g}, 1.1 \mathrm{mmol})$ in DMSO $(50 \mathrm{~mL})$ was placed into a 0.25 -L stirred reactor. The latter was fed with acetylene under pressure (initial pressure at ambient temperature was 12-14 atm and then decompressed to atmospheric pressure to remove air). The reactor was fed with acetylene again and heated $\left(70^{\circ} \mathrm{C}\right)$ for $8 \mathrm{~h}$. The reaction mixture, after cooling to room temperature, was diluted with cool $\left(5-7^{\circ} \mathrm{C}\right)$ water $(50 \mathrm{~mL})$ and extracted with diethyl ether $(15 \mathrm{~mL} \times 5)$. The extract was washed with water $(20 \mathrm{~mL} \times 3)$ and dried $\left(\mathrm{K}_{2} \mathrm{CO}_{3}\right)$ for $3 \mathrm{~h}$. After removal of the solvent, a crude residue was separated by column chromatography (basic $\mathrm{Al}_{2} \mathrm{O}_{3}$ ): first dioxabicyclooctane 3 was washed off with hexane, and then cyclopentenol 4 was washed off with $\mathrm{CHCl}_{3}$.

Bicyclooctane 3a (0.89 g, 36\%, yellow oil) and cyclopentenol 4a (1.54 g, 62\%, colorless crystals; $\mathrm{mp}=132-133{ }^{\circ} \mathrm{C}$, lit. ${ }^{28} 132-134{ }^{\circ} \mathrm{C}$ ) were obtained from $2.00 \mathrm{~g}$ of ketone $\mathbf{1 a}$.

Bicyclooctane 3a (4.6 g, 38\%) and cyclopentenol 4a (5.5 g, 45\%) were obtained from $10.0 \mathrm{~g}$ of ketone $1 \mathrm{a}$ and $0.54 \mathrm{~g} \mathrm{KOH} \cdot 0.5 \mathrm{H}_{2} \mathrm{O}$.

Bicyclooctane 3b (0.75 g, 25\%, yellow oil) and cyclopentenol 4b (1.53 g, 51\%, yellow oil) were obtained from $2.55 \mathrm{~g}$ of ketone $\mathbf{1 b}$.

Bicyclooctane 3c (0.98 g, 35\%, yellow crystals; $\mathrm{mp}=134-137{ }^{\circ} \mathrm{C}$, lit. $\left.{ }^{18} 136-138{ }^{\circ} \mathrm{C}\right)$ and cyclopentenol 4c (1.76 g, 63\%, colorless crystals; $\mathrm{mp}=212-213{ }^{\circ} \mathrm{C}$, lit. $\left.{ }^{28} 211-214{ }^{\circ} \mathrm{C}\right)$ were obtained from $2.89 \mathrm{~g}$ of ketone $\mathbf{1 c}$.

Bicyclooctane 3d (1.03 g, 41\%, white crystals, $\mathrm{mp}=119-120{ }^{\circ} \mathrm{C}$, lit. $\left.{ }^{44} 116-120{ }^{\circ} \mathrm{C}\right)$ and cyclopentenol $4 \mathbf{d}^{\prime}\left(0.88 \mathrm{~g}, 55 \%\right.$, yellow crystals; $\mathrm{mp}=101-102{ }^{\circ} \mathrm{C}$, lit. $\left.{ }^{28} 101-102{ }^{\circ} \mathrm{C}\right)$ were obtained from $2.06 \mathrm{~g}$ of ketone $\mathbf{1 d}$.

Bicyclooctane 3e (0.44 g, 17\%, white crystals; $\mathrm{mp}=112-113{ }^{\circ} \mathrm{C}$, lit. $\left.{ }^{18} 110-112{ }^{\circ} \mathrm{C}\right)$ and cyclopentenol $4 \mathrm{e}(1.42 \mathrm{~g}, 55 \%$, brown oil) were obtained from $2.15 \mathrm{~g}$ of ketone $1 \mathrm{e}$. 


\section{Typical procedure for the reaction of diketones $5 \mathrm{a}, \mathrm{b}$ with acetylene $\mathbf{2 a}$.}

The reaction of 1,5-diketones $\mathbf{5 a}, \mathbf{b}$ with acetylene 2a was carried out analogously to the described above procedure with $6 \mathrm{mmol}$ of 1,5-diketone $\mathbf{5 a}, \mathbf{b}, 3 \mathrm{mmol}(0.2 \mathrm{~g})$ of $\mathrm{KOH} \cdot 0.5 \mathrm{H}_{2} \mathrm{O}$ in DMSO $(50 \mathrm{~mL})$.

Bicyclooctane 3a (0.54 g, 31\%) and cyclopentenol 4a (1.14 g, 65\%) were obtained from $1.60 \mathrm{~g}$ of diketone $\mathbf{5 a}$.

Bicyclooctane 3f $\left(0.51 \mathrm{~g}, 24 \%\right.$, colorless crystals; mp $=77-78{ }^{\circ} \mathrm{C}$, lit. $\left.{ }^{19} 77-78{ }^{\circ} \mathrm{C}\right)$ and cyclopentenol $4 \mathbf{f}\left(0.77 \mathrm{~g}, 36 \%\right.$, colorless crystals; $\mathrm{mp}=218-219{ }^{\circ} \mathrm{C}$, lit. $\left.{ }^{28} 219{ }^{\circ} \mathrm{C}\right)$ were obtained from $2.00 \mathrm{~g}$ of diketone $\mathbf{5 b}$.

Typical procedure for the reaction of 1,5 -diketones $5 \mathrm{a}-\mathrm{c}$ with phenylacetylene $\mathbf{2 b}$.

A suspension of 1,5-diketone $5(6 \mathrm{mmol})$ and $\mathrm{KOH} \cdot 0.5 \mathrm{H}_{2} \mathrm{O}(0.2 \mathrm{~g}, 3 \mathrm{mmol})$ in DMSO $(40 \mathrm{~mL})$ was heated $\left(70{ }^{\circ} \mathrm{C}\right)$ upon stirring. Then phenylacetylene $2 \mathbf{b}(0.8 \mathrm{~g}, 7.7 \mathrm{mmol})$ in DMSO $(10 \mathrm{~mL})$ was added for $20 \mathrm{~min}$. The reaction mixture was heated for $3 \mathrm{~h}$ and, after cooling to room temperature, was diluted with $\mathrm{H}_{2} \mathrm{O}(100 \mathrm{~mL})$ and extracted with $\mathrm{Et}_{2} \mathrm{O}(20 \mathrm{~mL} \times 7)$. The extract was washed with water $(20 \mathrm{~mL} \times 3)$ and dried $\left(\mathrm{K}_{2} \mathrm{CO}_{3}\right)$ for $3 \mathrm{~h}$. After removal of the solvent, a crude residue was separated by column chromatography (basic $\mathrm{Al}_{2} \mathrm{O}_{3}$ ): first dioxabicyclooctane 3 was washed off with hexane, and then cyclopentenols $\mathbf{4}$ and $\mathbf{4}^{\prime}$ were washed off with $\mathrm{CHCl}_{3}$.

Bicyclooctane 3g $\left(0.66 \mathrm{~g}, 30 \%\right.$, colorless crystals; $\mathrm{mp}=97-99^{\circ} \mathrm{C}$, lit. $\left.{ }^{19} 97{ }^{\circ} \mathrm{C}\right)$, cyclopentenol $\mathbf{4 g}$ $\left(0.29 \mathrm{~g}, 13 \%\right.$, yellow crystals; $\mathrm{mp}=98-99{ }^{\circ} \mathrm{C}$, lit. $\left.{ }^{28} 96-99{ }^{\circ} \mathrm{C}\right)$ and cyclopentenol $\mathbf{4 \mathbf { g } ^ { \prime }}(0.63 \mathrm{~g}$, $40 \%$, yellow oil) were obtained from $1.60 \mathrm{~g}$ of diketone $\mathbf{5 a}$.

Bicyclooctane $3 \mathbf{h}\left(0.41 \mathrm{~g}, 16 \%\right.$, colorless crystals, $\mathrm{mp}=87-88{ }^{\circ} \mathrm{C}$, lit. $\left.{ }^{19} 87-88{ }^{\circ} \mathrm{C}\right)$, cyclopentenol 4h $\left(0.52 \mathrm{~g}, 20 \%\right.$, colorless crystals; $\mathrm{mp}=202-204^{\circ} \mathrm{C}$, lit. $\left.{ }^{28} 204-207^{\circ} \mathrm{C}\right)$ and cyclopentadiene $\mathbf{4 h}$ " $\left(0.93 \mathrm{~g}, 50 \%\right.$, yellow crystals; $\mathrm{mp}=75-76{ }^{\circ} \mathrm{C}$, lit. $\left.{ }^{28} 75-76{ }^{\circ} \mathrm{C}\right)$ were obtained from $2.00 \mathrm{~g}$ of diketone $\mathbf{5 b}$.

Cyclopentenol 4i (1.40 g, 66\%, colorless crystals; $\mathrm{mp}=102-103{ }^{\circ} \mathrm{C}$, lit. $\left.{ }^{28} 102-105{ }^{\circ} \mathrm{C}\right)$ and cyclopentenol 4i' (0.38 g, 25\%, yellow oil) were obtained from $1.51 \mathrm{~g}$ of diketone $\mathbf{5 c}$.

\section{Acknowledgements}

This work was supported by a grant of Russian Scientific Foundation (project №14-13-00588).

\section{References}

1. Schobert, H. Chem. Rev. 2014, 1743. http://dx.doi.org/10.1021/cr400276u

2. Trotuş, I.-T.; Zimmermann, T.; Schüth, F. Chem. Rev. 2014, 1761. http://dx.doi.org/10.1021/cr400357r 
3. Chinchilla, R.; Nájera, C. Chem. Rev. 2014, 1783.

http://dx.doi.org/10.1021/cr400133p

4. Salvio, R.; Moliterno, M.; Bella, M. Asian J. Org. Chem. 2014, 3, 340. http://dx.doi.org/10.1002/ajoc.201400021

5. Li, G.; Liu, Q.; Liu, Z.; Zhang, Z. C.; Li, C.; Wu, W. Angew. Chem. Int. Ed. 2010, 49, 84808483.

http://dx.doi.org/10.1002/anie.201004169

6. Camp, J. Chemistry Today Catalysis Applications 2012, 30, 6.

7. Ngwerume, S.; Lewis, W.; Camp, J. E. J. Org. Chem. 2013, 78, 920.

http://dx.doi.org/10.1021/jo302349k

8. Maretina, I. A.; Ionin, B. I. In Alkynes in Cycloadditions; Tebby, J. C. Ed.; Wiley-VCH: Weinheim, 2014; pp 6-13, 29-33.

9. Heller, B.; Hapke, M. Chem. Soc. Rev. 2007, 36, 1085. http://dx.doi.org/10.1039/b607877j

10. Dazinger, G.; Torres-Rodriguez, M.; Kirchner, K.; Calhorda, M. J.; Costa, P. J. J. Organomet. Chem. 2006, 691, 4434.

http://dx.doi.org/10.1016/j.jorganchem.2006.03.004

11. Tedeschi R. J. In Encyclopedia of physical science and technology; Academic Press, Inc.: San Diego, 1992; Vol. 1, pp 37-38.

12. Bauer, K.; Garbe, D.; Surburg, H. In Common fragrance and flavor materials: Preparation, properties and uses; John Wiley \& Sons: Weinheim, 2008; p 36.

13. Wittcoff, H. A.; Reuben, B. G.; Plotkin, J. S. In Industrial organic chemicals; John Wiley \& Sons: Weinheim, 2012; p 424.

14. Diederich, F.; Stang, P. J.; Tykwinski, R. R. In Acetylene chemistry: Chemistry, biology and material science; John Wiley \& Sons: Weinheim, 2006; pp 105-106.

15. Trofimov, B. A. Curr. Org. Chem. 2002, 6, 1121.

http://dx.doi.org/10.2174/1385272023373581

16. Trofimov, B. A.; Schmidt, E. Yu.; Skital'tseva, E. V.; Zorina, N. V.; Protsuk, N. I.; Ushakov, I. A.; Mikhaleva, A. I.; Dyachenko, O. A.; Kazheva, O. N.; Aleksandrov, G. G. Tetrahedron Lett. 2011, 52, 4285.

http://dx.doi.org/10.1016/j.tetlet.2011.06.019

17. Trofimov, B. A.; Mikhaleva, A. I.; Schmidt, E. Yu.; Sobenina, L. N. Adv. Heterocycl. Chem. 2010, 99, 209.

http://dx.doi.org/10.1016/S0065-2725(10)09907-1

18. Trofimov, B. A.; Schmidt, E. Yu.; Ushakov, I. A.; Mikhaleva, A. I.; Zorina, N. V.; Protsuk, N. I.; Senotrusova, E. Yu.; Skital'tseva, E. V.; Kazheva, O. N.; Aleksandrov, G. G.; Dyachenko, O. A. Eur. J. Org. Chem. 2009, 5142.

http://dx.doi.org/10.1002/ejoc.200900853 
19. Schmidt, E. Yu.; Bidusenko, I. A.; Protsuk, N. I.; Ushakov, I. A.; Trofimov, B. A. Eur. J. Org. Chem. 2013, 2453.

http://dx.doi.org/10.1002/ejoc.201201700

20. Schmidt, E. Yu.; Tatarinova, I. V.; Ivanova, E. V.; Zorina, N. V.; Ushakov, I. A.; Trofimov, B. A. Org. Lett. 2013, 15, 104. http://dx.doi.org/10.1021/o1303132u

21. Trofimov, B. A.; Schmidt, E. Yu.; Mikhaleva, A. I.; Ushakov, I. A.; Protsuk, N. I.; Senotrusova, E. Yu.; Kazheva, O. N.; Aleksandrov, G. G.; Dyachenko, O. A. Tetrahedron Lett. 2009, 50, 3314.

http://dx.doi.org/10.1016/j.tetlet.2009.02.085

22. Trofimov, B. A.; Gusarova, N. K. Russ. Chem. Rev. 2007, 76, 507.

http://dx.doi.org/10.1070/RC2007v076n06ABEH003712

23. Trofimov, B. A.; Schmidt, E. Yu. Russ. Chem. Rev. 2014, 83, 600. http://dx.doi.org/10.1070/RC2014v083n07ABEH004425

24. Perrin, T. E.; Rasmussen, L. E. L.; Gunawardena, R.; Rasmussen, R. A. J. Chem. Ecol. 1996, 22, 207. http://dx.doi.org/10.1007/BF02055093

25. Rasmussen, L. E. L.; Riddle, H. S.; Krishnamurthy, V. Nature 2002, 415, 975. http://dx.doi.org/10.1038/415975a

26. Deeds, J. R.; Schwartz, M. D. Toxicon 2010, 56, 150. http://dx.doi.org/10.1016/j.toxicon.2009.05.035

27. Ramos, V.; Vasconcelos, V. Marine Drugs 2010, 8, 2021. http://dx.doi.org/10.3390/md8072021

28. Schmidt, E. Yu.; Trofimov, B. A.; Bidusenko, I. A.; Cherimichkina, N. A.; Ushakov, I. A.; Protzuk, N. I.; Gatilov, Yu. V. Org. Lett. 2014, 16, 4040. http://dx.doi.org/10.1021/ol501881e

29. Williams, R. T.; Yu, A. L.; Diccianni, M. B.; Theodorakis, E. A.; Batova, A. Journal of Experimental \& Clinical Cancer Research, 2013, 32, 57.

http://dx.doi.org/10.1186/1756-9966-32-57

30. Wood, J. L.; Pujanauski, B. G.; Sarpong, R. Org. Lett. 2009, 11, 3128. http://dx.doi.org/10.1021/o19010008

31. Krishna, P. R.; Kadiyala, R. R. Tetrahedron Lett. 2010, 51, 4981. http://dx.doi.org/10.1016/j.tetlet.2010.07.081

32. Cho, J. H.; Bernard, D. L.; Sidwel, R. W.; Kern, E. R.; Chu, C. K. J. Med. Chem. 2006, 49, 1140 . http://dx.doi.org/10.1021/jm0509750

33. Parker, W. B.; White, E. L.; Shaddix, S. C.; Ross, L. J.; Buckheit, R. W.; Germany, J. M.; Secrist, J. A.; Vincell, R.; Shannon, W. M. J. Biol. Chem. 1991, 266, 1754.

34. Nayek, A.; Banerjee, S.; Sinha, S.; Ghosh, S. Tetrahedron Lett. 2004, 45, 6457. http://dx.doi.org/10.1016/j.tetlet.2004.06.127 
35. Chi, Y.; Gellman, S. H. Org. Lett. 2005, 7, 4253.

http://dx.doi.org/10.1021/o10517729

36. Shankar, R.; Jha, A. K.; Singh, U. S.; Hajela, K. Tetrahedron Lett. 2006, 47, 3077. http://dx.doi.org/10.1016/j.tetlet.2006.03.008

37. Yanagisawa, A.; Takahashi, H.; Arai, T. Tetrahedron 2007, 63, 8581. http://dx.doi.org/10.1016/j.tet.2007.04.079

38. Tilichenko, M. N. Russ. J. Gen. Chem. 1955, 25, 2503.

39. Mounet, J.; Huet, J.; Dreux, J. Bull. Soc. Chim. Fr. 1970, 1170.

40. Nagayama, K.; Kumar, A.; Wuthrich, K.; Ernst, R. R. J. Magn. Reson. 1980, 40, 321.

41. Wagner, G.; Wuthrich, K. J. Mol. Biol. 1982, 155, 347. http://dx.doi.org/10.1016/0022-2836(82)90009-2

42. Bodenhausen, G.; Ruben, D. J. Chem. Phys. Lett. 1980, 69, 185. http://dx.doi.org/10.1016/0009-2614(80)80041-8

43. Bax, A.; Summers, M. F. J. Am. Chem. Soc. 1986, 108, 2093. http://dx.doi.org/10.1021/ja00268a061

44. Trofimov, B. A.; Schmidt, E. Yu.; Bidusenko, I. A.; Ushakov, I. A.; Protsuk, N. I.; Zorina, N. V.; Mikhaleva, A. I. Tetrahedron 2012, 68, 1241. http://dx.doi.org/10.1016/j.tet.2011.11.050 